\title{
New 15-mL ventricular assist device in children with restrictive physiology of the left ventricle
}

\author{
Santosh Sundararajan, MD, Timothy Thiruchelvam, MB, ChB, Tain-Yen Hsia, MD, and \\ Ann Karimova, MD, London, United Kingdom
}

The Berlin Heart Pediatric EXCOR (Berlin Heart GmbH, Berlin, Germany) ventricular assist device (VAD) has been successfully used as a bridge to orthotopic heart transplant (OHT) in infants and children. ${ }^{1-3}$ The 10- and $25-\mathrm{mL}$ volume pumps have improved outcomes in children weighing less than $10 \mathrm{~kg},{ }^{2,3}$ although their risk of mortality remains higher relative to larger children. ${ }^{3}$ The risk of VAD-related complications may also be higher when the chamber volume is not appropriately matched to the patient size. ${ }^{4}$

Restrictive left ventricular (LV) physiology presents a unique challenge for left VAD (LVAD) implantation in children because of potential problems with drainage with conventional LV apical cannulation. We describe the use of a novel $15-\mathrm{mL}$ volume Berlin Heart Pediatric EXCOR VAD in 2 children with restrictive $\mathrm{LV}$.

\section{CLINICAL SUMMARIES}

Patient 1 was a female patient, diagnosed with LV noncompaction cardiomyopathy with restrictive features in infancy. By 2 years, she had significant left atrial (LA) and LV dilatation ( $z$ scores of +9.78 and +5.36 , respectively) with severe mitral regurgitation (Figure 1). Cardiac catheterization confirmed a mean LA pressure of $44 \mathrm{~mm}$ $\mathrm{Hg}$ and elevated pulmonary vascular resistance index of 9 Wood units $/ \mathrm{m}^{2}$, decreasing to 3.2 Wood units $/ \mathrm{m}^{2}$ with inhaled nitric oxide and oxygen. At 33 months of age, after lack of response to pharmacologic therapy on intensive care, she was placed on extracorporeal membrane oxygenation support. After 6 days on extracorporeal membrane oxygenation support, at a weight of $9.6 \mathrm{~kg}$ and body surface area of $0.48 \mathrm{~m}^{2}$, the patient underwent LVAD implantation as bridge to OHT. A $15-\mathrm{mL}$ Pediatric EXCOR pump was implanted with LA-to-aorta cannulation because of the significant LA enlargement. The initial pump rate was

\footnotetext{
From the Cardiothoracic Unit, Great Ormond Street Hospital for Children, London, United Kingdom.

Disclosures: Authors have nothing to disclose with regard to commercial support.

Received for publication Jan 24, 2014; revisions received Feb 19, 2014; accepted for publication Feb 28, 2014; available ahead of print March 29, 2014.

Address for reprints: Santosh Sundararajan, MD, Cardiothoracic Unit, Great Ormond Street Hospital for Children, Great Ormond St, London WC1N 3JH, United Kingdom (E-mail: santosh.sundararajan@gosh.nhs.uk).

J Thorac Cardiovasc Surg 2014;147:e79-80

0022-5223/\$36.00

Copyright (c) 2014 by The American Association for Thoracic Surgery

http://dx.doi.org/10.1016/j.jtcvs.2014.02.083
}

80 to 100 beats $/ \mathrm{min}$, providing a cardiac index $(\mathrm{CI})$ between 2.5 and $3.1 \mathrm{~L} / \mathrm{min} / \mathrm{m}^{2}$. She was successfully extubated on day 23 after LVAD implantation and remained free of complications. After 3 months on support, the patient's weight had increased to $13 \mathrm{~kg}$ (pump rate of 120 beats $/ \mathrm{min}$ for a CI of $3.0 \mathrm{~L} / \mathrm{min} / \mathrm{m}^{2}$ ), and she started having sweaty episodes on exertion. On the basis of echocardiographic evidence of elevated LV end-diastolic volume, the pump was upsized to $25 \mathrm{~mL}$ (pump rate of 80 beats/min for a CI of $3.3 \mathrm{~L} / \mathrm{min} / \mathrm{m}^{2}$ ). After a total of 131 days of LVAD support, the patient underwent uncomplicated OHT. She was successfully extubated on day 3 after transplant and discharged from intensive care on day 6 .

Patient 2 was a male patient with a diagnosis of restrictive cardiomyopathy with biventricular involvement at the age of 11 months (weight of $10 \mathrm{~kg}$ and body surface area of $0.43 \mathrm{~m}^{2}$ ). His condition worsened during the course of several weeks, necessitating admission to intensive care. Echocardiography demonstrated biatrial enlargement ( $z$ score of +4.29 ) with high LV end-diastolic pressure $(17 \mathrm{~mm} \mathrm{Hg}$ ) on cardiac catheterization. The patient was listed for OHT, and a $15-\mathrm{mL}$ LVAD and a $15-\mathrm{mL}$ right VAD were inserted after 12 days of intensive care. LVAD drainage was through the LA. His chest was closed on postoperative day 6 , and he was successfully extubated on day 13. The patient has been on VAD support for 5 months, with pump rates ranging from 85 to 115 beats $/ \mathrm{min}$ and CIs ranging from 2.6 to $3.5 \mathrm{~L} / \mathrm{min} / \mathrm{m}^{2}$, and is currently awaiting a donor organ.

\section{DISCUSSION}

Worldwide, more than half of the children supported with the EXCOR VAD weigh less than $10 \mathrm{~kg} .^{1-3}$ The waiting time for OHT may be longer ${ }^{3}$ and the risk of mortality higher ${ }^{2}$ for these smaller children. Children at the upper end of this weight range need an estimated 1000 to $1500 \mathrm{~mL} / \mathrm{min}$ of cardiac output to decompress the LV, meet metabolic demands, and thrive. Until recently, they have been supported either with a $10-\mathrm{mL} \mathrm{VAD}$, resulting in small stroke volumes at higher pump rates, or with a $25-\mathrm{mL}$ $\mathrm{VAD}$, delivering larger stroke volumes at lower pump rates but often accompanied by lower diastolic pressure. The consequences of such physiologic anomalies are unclear; however, mismatch between chamber volume and body size may contribute to VAD-related complications. ${ }^{4}$ 

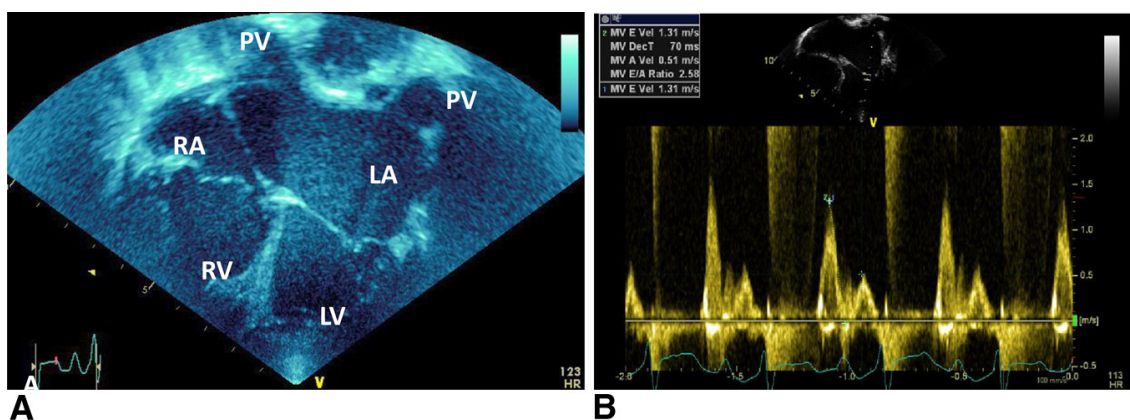

FIGURE 1. Echocardiographic studies of patient 1 with left ventricular $(L V)$ noncompaction cardiomyopathy before left ventricular assist device implantation. A, Apical 4-chamber demonstrating severe left atrial $(L A)$ dilation and pulmonary vein $(P V)$ congestion. B, Mitral inflow Doppler trace with short deceleration time. $R A$, Right atrium; $R V$, right ventricle; $M V$, mitral valve; $E$ Vel, peak E wave velocity; $D e c T$, deceleration time; $A$ Vel, peak A wave velocity; E/A ratio, ratio of peak $E$ wave velocity to peak A wave velocity.

We describe the successful use of a new $15-\mathrm{mL}$ EXCOR pump in 2 children whose requirements fell between the ideal fill and flow characteristics of the existing pumps. In children with a body surface area ranging from 0.33 to $0.55 \mathrm{~m}^{2}$ and weight ranging from 7 to $12 \mathrm{~kg}$, the $15-\mathrm{mL}$ chamber complements the EXCOR infant range. It can achieve a CI of 2.7 to $3.3 \mathrm{~L} / \mathrm{min} / \mathrm{m}^{2}$ at pump rates of 60 to 120 beats/min.

Restrictive and noncompaction cardiomyopathies are rare but contribute disproportionately to mortality in children with cardiomyopathy. ${ }^{2,3,5}$ Conventional VAD cannulation of the noncompliant LV often results in insufficient drainage, with concomitant poor pump performance, and residual LA hypertension, with subsequent pulmonary congestion. In these patients, the LA/LV disproportion with preservation of systolic function makes LA cannulation an attractive option, perhaps with less risk of ventricular thrombus formation than in dilated cardiomyopathies.
Optimal pump sizing could aid an uninterrupted drainage, and these patients could benefit most from the versatility offered by the additional chamber size.

\section{References}

1. Fraser CD Jr, Jaquiss RD, Rosenthal DN, Humpl T, Canter CE, Blackstone EH, et al. Prospective trial of a pediatric ventricular assist device. $N$ Engl J Med. 2012;367:532-41

2. Cassidy J, Dominguez T, Haynes S, Burch M, Kirk R, Hoskote A, et al. A longer waiting game: bridging children to heart transplant with the Berlin Heart EXCOR device-the United Kingdom experience. J Heart Lung Transplant. 2013;32: 1101-6.

3. Almond CS, Morales DL, Blackstone EH, Turrentine MW, Imamura M, Massicotte MP, et al. Berlin Heart EXCOR pediatric ventricular assist device for bridge to heart transplantation in US children. Circulation. 2013;127:1702-11.

4. Husain SA, Wallis G, Fricker FJ, Bleiweis MS, Staples ED, Klodell CT, et al. Ventricular assist device implantation in the pediatric population: does pump size selection and associated hemodynamics impact outcomes? ASAIO J. 2008; 54:474-8.

5. Zangwill SD, Naftel D, L'Ecuyer T, Rosenthal D, Robinson B, Kirklin JK, et al. Outcomes of children with restrictive cardiomyopathy listed for heart transplant: a multi-institutional study. J Heart Lung Transplant. 2009;28:1335-40.

\title{
Avoidance of completion pneumonectomy by sparing the right middle lobe
}

\author{
Thomas Fabian, MD, FCCP, and Jeremy W. Docekal, MD, Albany, NY
}

\footnotetext{
From the Albany Medical Center, Albany, NY.

Disclosures: Thomas Fabian reports consulting and lecture fees from Covidien. The other author has nothing to disclose with regard to commercial support.

Received for publication July 22, 2013; revisions received Feb 27, 2014; accepted for publication March 3, 2014; available ahead of print April 1, 2014.

Address for reprints: Thomas Fabian, MD, FCCP, Albany Medical Center, 50 New Scotland Ave, mc-1548290455, Albany, NY 12208 (E-mail: FabianT@mail.amc. edu).

J Thorac Cardiovasc Surg 2014;147:e80-2

$0022-5223 / \$ 36.00$

Copyright (c) 2014 by The American Association for Thoracic Surgery

http://dx.doi.org/10.1016/j.jtcvs.2014.03.004
}

Metachronous primary lung cancers (MPLCs) are defined as separate, unrelated lung cancers occurring at different times. Surgical resection remains a viable treatment option for patients with MPLCs. In patients with a history of lobectomy for the earlier ipsilateral MPLC, an additional lobectomy creates the perceived need for a completion pneumonectomy. On the right side, sparing the right middle lobe by itself is considered inappropriate by most. We challenged this common principle in treating a relatively high-risk patient. 